\title{
A TECNOLOGIA EM SENTIDO MORAL: UMA PERSPECTIVA CRÍTICA EM ROUSSEAU
}

\author{
Antonio Carlos Borges da Silva ${ }^{1}$ \\ Conceição de Maria Belfort Carvalho ${ }^{2}$ \\ Ezenilde Rocha Mendes ${ }^{3}$ \\ Luciano da Silva Façanha ${ }^{4}$
}

\begin{abstract}
Resumo:
O presente artigo pretende fazer uma análise reflexiva sobre a tecnologia em sentido moral. Procura-se abordar o desenvolvimento das tecnologias evidenciando suas implicações morais a partir da crítica ao progresso da razão elaborada por Jean-Jacques Rousseau no Discurso sobre as ciências $e$ as artes. Assume-se a perspectiva crítica rousseauniana no sentido de que se compreende que o progresso científico e tecnológico deve ser entendido do ponto de vista da sua causalidade final na medida em que o progresso está relacionado com transformações profundas que ocorrem nas relações entre o homem, a natureza e a sociedade.
\end{abstract}

Palavras-chave: Homem. Tecnologia. Moral. Rousseau.

\section{THE TECHNOLOGY ON MORAL SENSE: A CRITICAL PERSPECTIVE ON ROUSSEAU}

\begin{abstract}
:
This article intends to make a reflexive analysis about technology in the moral sense. It seeks to address the development of technologies by showing its moral implications from the criticism of the progress of reason elaborated by Jean-Jacques Rousseau in his Discourse on Sciences and the Arts. The critical Rousseauian perspective is assumed in the sense that it is understood that scientific and technological progress must be understood from the point of view of its ultimate causality insofar as progress is related to the profound transformations that occur in the relations between man, nature and society.
\end{abstract}

Keywords: Man. Technology. Moral. Rousseau.

\section{Introdução}

O presente artigo pretende analisar reflexivamente o tema da tecnologia em seu sentido moral. Procura-se abordar o desenvolvimento das tecnologias evidenciando suas implicações morais especialmente a partir da crítica ao progresso da razão elaborada por

1 Mestre em Cultura e sociedade pela Universidade Federal do Maranhão. Membro participante do Grupo de Estudo e Pesquisa Interdisciplinar Jean-Jacques Rousseau (GEPI ROUSSEAU/UFMA) vinculado ao CNPq. Email: carlosfile@yahoo.com.br.

2 Doutora em Linguística e Língua Portuguesa pela Universidade Estadual Paulista Júlio de Mesquita Filho (2009). Professora do Programa de Pós-Graduação em Cultura e Sociedade da Universidade Federal do Maranhão. E-mail: cbelfort@globo.com.

3 Mestra em Cultura e Sociedade, pela Universidade Federal do Maranhão (UFMA); membro do Grupo de Estudo e Pesquisa Interdisciplinar Jean-Jacques Rousseau (GEPI Rousseau). E-mail: ezenilderocha@gmail.com.

4 Pós-Doutor em Filosofia pela Pontifícia Universidade Católica de São Paulo. Doutor em Filosofia pela PUCSP. Professor Associado do Departamento de Filosofia e do Programa de Pós-Graduação em Cultura e Sociedade da Universidade Federal do Maranhão - UFMA. E-mail: lucianosfacanha@ hotmail.com. 
Rousseau no Discurso sobre as ciências e as artes. Assume-se a perspectiva crítica rousseauniana no sentido de que a compreensão do progresso científico e tecnológico deve ser entendido enquanto causalidade final na medida em que o progresso está na causa das profundas transformações nas relações entre o homem, a natureza e a sociedade.

Dessa forma, a reflexão será desenvolvida a partir de alguns questionamentos sobre os juízos morais que possam ser feitos acerca da técnica bem como em que medida, na sociedade da técnica, pode-se pensar se a tecnologia tem contribuído para o desenvolvimento humano integral ou apenas para a exploração do homem.

O progresso da técnica tem efetivamente melhorado o homem? A tecnologia não estaria contribuindo para o aprofundamento das desigualdades na medida em que por ela a segregação socioeconômica tem se acentuado no decorrer do século XXI?

Um dos aspectos mais evidentes da filosofia do século XVIII era a história do desenvolvimento da razão sob uma perspectiva otimista de sua ação potencializadora no que concerne ao melhoramento das condições da vida humana. Como se verá, o filósofo JeanJacques Rousseau se diferenciará desta concepção de progresso. Para o filósofo, o progresso é o espaço de declínio do homem. É o retrato de seu fracasso enquanto espécie. Pois, apesar de ele ser o único animal inteligente, é também o único animal capaz de se auto destruir.

Mesmo considerando que o contexto em que Rousseau escreveu seu primeiro Discurso difere do contexto contemporâneo, entende-se que este tema apesar de ter perdido sua atualidade histórica, não perdeu sua atualidade ontológica.

Desse modo, ainda é possível verificar as consequências das modificações na cultura analisadas por Rousseau. A contemporaneidade ainda vive sob o signo do progresso muito embora as pessoas em geral não demonstrem mais o mesmo otimismo ingênuo característico do século XVIII; não obstante, ainda persiste o esforço intelectual humano no sentido da dominação da natureza mediada pelo conhecimento, que por sua vez, alimenta uma revolução intelectual cujos objetivos técnico-econômicos constituem sua verdadeira finalidade.

\section{A Sociedade da técnica}

O Século XX começou a elaborar novas maneiras de pensamento e de reflexão acerca do mundo no contexto das telecomunicações e da informática. Novas maneiras de pensar e de conviver estão sendo elaboradas no mundo das telecomunicações e da informação.

\begin{tabular}{|l|l|l|l|l|}
\hline Qevista Dialectus & Ano 8 & n. 15 & Agosto - Dezembro 2019 & p. $171-180$ \\
\hline
\end{tabular}


Diante dessas mudanças, houve uma reconfiguração das inteligências que passaram a ser comandadas por dispositivos informacionais. Na contemporaneidade, a técnica assume dimensões fundamentais nas relações do homem com o mundo. Cada vez mais se pode perceber a acentuação doas aspectos tecnoecômicos e sua interferência em todas as esferas da vida social. Diante desta constatação, resta o reconhecimento da atuação cada vez maior dessas realidades tecnoeconômicas nas esferas intelectual e social. Tudo isso leva ao reconhecimento de que a técnica é um dos temas mais importantes de nossa época, quer seja do ponto de vista político quer do ponto de vista econômico. (LÉVY, 1993).

Segundo Castells (2003, p. 7):

O que caracteriza a revolução tecnológica atual não é o caráter central do conhecimento e da informação, mas a aplicação deste conhecimento e informação a aparatos de geração de conhecimento e processamento da informação/comunicação em um círculo de retroalimentação acumulativa entre a inovação e seus usos". A difusão da tecnologia amplifica infinitamente seu poder ao se apropriar de seus usuários e redefini-los.

Lévy (1993, p. 10) considera ainda que:

Iniciada no fim do século XVIII, a presente mutação antropológica somente pode ser comparada à revolução neolítica que viu surgirem, em poucos séculos, a agricultura, a criação de animais, a cidade, o Estado e a escrita. Dentre todas as transformações fundamentais que afetaram os países desenvolvidos na época atual, ressaltemos o desaparecimento do mundo agrícola, o apagamento da distinção cidade/campo e [consequente] surgimento de uma rede urbana onipresente, um novo imaginário do espaço e do tempo sob a influência das metas de transporte rápidos e da organização industrial do trabalho, o deslocamento das atividades econômicas para o terciário e a influência cada vez mais direta da pesquisa científica sobre as atividades produtivas e os modos de vida.

\section{Jean-Jacques Rousseau e a crítica ao progresso das ciências e das artes}

No Século XVIII havia um embate entre os teóricos no sentido de que muitos deles tinham diferentes concepções acerca da sociedade e do homem. Porém, essas concepções tinham um aspecto em comum, a saber, o fato de que as sociedades, tal como tinham se estabelecido estavam, em geral, afastadas de uma ideia de natureza humana; eram sistemas de competição em que os indivíduos que buscavam sua autoafirmação em oposição aos demais. Para Rousseau, essa competição era possibilitada pelo desenvolvimento das ciências e das artes e tinha como resultado o aumento das desigualdades entre os homens.

\begin{tabular}{|l|l|l|l|l|}
\hline Qevista Dialectus & Ano 8 & n. 15 & Agosto - Dezembro 2019 & p. $171-180$ \\
\hline
\end{tabular}


Em 1750, a Academia de Dijon (França) realizou um concurso no qual era indagado se o restabelecimento das ciências e das artes contribuiu para o aperfeiçoamento ou corrupção dos costumes. Desse modo, a Academia propunha que fosse feita a relação entre o progresso e as virtudes humanas.

Rousseau inicia seu Discurso perguntando retoricamente qual partido deverá tomar para responder à questão proposta pela Academia. A crítica rousseauniana dirige-se aos efeitos do progresso. Um dos primeiros efeitos constatados é o fato de que, na sociedade, o conhecimento é uma forma de se obter reconhecimento e prestígio:

O restabelecimento das ciências e das artes contribuiu para aprimorar ou corromper os costumes? Eis o que é preciso examinar. Que partido deverei tomar nessa questão? Aquele, senhores, que convém a um homem de bem que nada sabe e que nem por isso se despreza (ROUSSEAU, 1983, p. 233).

Na primeira parte do Discurso sobre as ciências e as artes, Rousseau (1983, p. 330) faz um elogio à razão humana por ter tirado o homem das trevas da ignorância em que ele vivia no estado primitivo:

É um espetáculo grandioso e belo ver o homem sair, por seu próprio esforço, a bem dizer do nada: dissipar, por meio das luzes de sua razão as trevas nas quais o envolveu a natureza; elevar-se acima de si mesmo: lançar pelo espírito a regiões celestes, percorrer com passos de gigantes, como o sol, as vastas extensões do universo; e, o que ainda é maior e mais difícil, penetrar em si mesmo para estudar o homem e conhecer sua natureza, seus deveres e seu fim [...].

Vê-se, desse modo, que Rousseau não se contrapõe à racionalidade humana. Pelo contrário, chega a reconhecer a relevância do progresso e das suas realizações culturais. Porém, não é essa questão que interessará ao filósofo. Com efeito, afirma Rousseau (1983, p. 333): "Não é a ciência que maltrato, [...], mas a virtude que defendo perante homens virtuosos".

Nesse momento, a crítica está centrada apenas nos meios pelos quais os homens se afirmam perante a natureza. Quanto a essa questão, não resta dúvida sobre o sucesso insofismável do progresso a que chegaram as civilizações por meio das sutilezas filosóficas, das realizações das ciências, das letras e do comércio.

Portanto, tem-se que até esse ponto do seu Discurso, ainda estão garantidas as (aparentes) concessões feitas ao progresso. O homem, sendo uma criatura desprovida de todas

\begin{tabular}{|l|l|l|l|l|}
\hline Qevista Dialectus & Ano 8 & n. 15 & Agosto - Dezembro 2019 & p. $171-180$ \\
\hline
\end{tabular}


as qualidades de que a natureza armou as outras espécies, no entanto, essa mesma natureza deulhe a razão, e com isso, diferenciou-o de todos os outros seres do reino animal.

Resta, porém, investigar, se, no que concerne ao progresso do homem mesmo, as coisas têm caminhado a bom termo. Antes de seguir o raciocínio, é necessário observar que o que Rousseau demonstra nas cadeias de sua argumentação é que ele visa a análise do homem de acordo com os meios e os fins sob a perspectiva moral. Para Rousseau (1983, p. 228) no entanto: "O mais útil e o menos avançado de todos os conhecimentos parece-me ser o do homem [...]." Rousseau observa, sagazmente, que não se trata de estudar aquilo que os homens têm feito em termos de progresso, mas sim de ver aquilo em que se transformaram por causa do progresso.

No Discurso Rousseau retrata em uma breve história dos homens demonstrando sua antítese entre o homem ignorante e feliz dos primeiros tempos e o homem educado e infeliz dos tempos modernos. No entanto, ainda há uma alternativa possível. Se as ciências são a causa da degeneração (que leva à infelicidade) do homem, cabe a elas, no entanto, serem seu antídoto, pois não se trata mais de renunciar ao conhecimento menos do que o conduzir e não se deixar conduzir por ele.

Não é mais possível ao homem recuperar seu estado anterior dado que a história mostra que o progresso é o resultado de sua própria natureza. Uma vez que os homens abraçaram as luzes da razão eles saíram do estado primitivo e lançaram-se a um caminho sem retorno, isto é, ao progresso. Portanto, para Rousseau, a ciência não é um mal em si mesma. Depende do uso que se fizer dela.

Desse modo, Rousseau analisa desenvolvimento histórico questionando a sua finalidade e utilidade (morais). Deve-se perceber, entretanto, que a utilidade para Rousseau tem um valor de felicidade para o homem. É útil, e, portanto, bom tudo aquilo que contribui para tornar o homem feliz. E a felicidade não é garantida por nenhuma forma de artificialidade, mas pela simplicidade da vida.

Defendemos, portanto, que o filósofo genebrino não toma o progresso no sentido do desenvolvimento da técnica. O que ele analisa não é o progresso técnico do homem, mas o homem que resultou desse progresso. Ou seja, a história dos desenvolvimentos técnicos, visita desse modo, é exatamente a expressão perfeita da degeneração da espécie.

\section{A sociedade contemporânea: a tecnologia como a nova metafísica}

\begin{tabular}{|l|l|l|l|l|}
\hline Qevista Dialectus & Ano 8 & n. 15 & Agosto - Dezembro 2019 & p. $171-180$ \\
\hline
\end{tabular}


O modo como as sociedades se organizam refletem uma concepção específica de homem; assim, em cada época, predomina a concepção que interesse a determinados grupos segundo os fins que almejam. Uma sociedade teocrática estabelecerá uma ideia de homem diferente de uma sociedade democrática. Mas todas as concepções de homem servirão para justificar um ideal de formação humana. Então, pode-se pensar como característica do homem da contemporaneidade, que esta seja sem dúvida, fundamentada na sua capacidade racional:

\begin{abstract}
Assim, computadores, sistemas de comunicação, decodificação e programação genética são todos amplificadores e extensões da mente humana. O que pensamos e como pensamos e expresso em bens, serviços, produção material e intelectual, sejam alimentos, moradia, sistemas de transporte e comunicação, mísseis, saúde, educação ou imagens. A integração crescente entre mentes e maquinas, inclusive a máquina de DNA, esta anulando o que Bruce Mazlish chama de a "quarta descontinuidade" 17 (aquela entre seres humanos e maquinas), alterando fundamentalmente o modo pelo qual nascemos, vivemos, aprendemos, trabalhamos, produzimos, consumimos, sonhamos, lutamos ou morremos. (CASTELLS, p. 69).
\end{abstract}

Santos (2008, p. 82) considera que:

O aprofundamento do conhecimento conduzido segundo a matriz materialista veio a desembocar num conhecimento idealista. A nova dignidade da natureza mais se consolidou quando se verificou que o desenvolvimento tecnológico desordenado nos tinha separado da natureza em vez de nos unir a ela e que a exploração da natureza tinha sido o veículo da exploração do homem.

Manuel Castells (2003) considerou uma verdadeira revolução as mudanças ocorridas no final do século XX. Para ele, a história da vida pode ser tomada como uma série de situações estáveis, pontuadas em intervalos raros por eventos importantes que ocorrem com grande rapidez e ajudam a estabelecer a próxima era estável.

Neste contexto, estabelece-se no século XX, uma nova era, inicialmente chamada de sociedade da informação, posteriormente de sociedade do conhecimento e atualmente como sociedade da aprendizagem, uma vez que não pode haver conhecimento sem aprendizagem e nela a fonte de produtividade encontra-se, portanto, na tecnologia de geração de conhecimentos.

Como bem aponta Castells:

O que caracteriza a atual revolução tecnológica não é a centralidade de conhecimentos e informação, mas a aplicação desses conhecimentos e dessa informação para a geração de conhecimentos e de dispositivos de processamento-comunicação da

\begin{tabular}{|l|l|l|l|l|}
\hline Qovista Qialectus & Ano 8 & n. 15 & Agosto - Dezembro 2019 & p. $171-180$ \\
\hline
\end{tabular}


informação, em um ciclo de realimentação cumulativo entre a inovação e o uso" (CASTELLS, 1999, p. 69).

Desse modo, a ideia da necessidade tecnológica está estritamente ligada à outra: a ideia de que se ela é útil, ela é boa em si mesma, e portanto, necessária. Desse modo o homem moderno é aquele sujeito que julgará o mundo baseado em uma concepção pragmática e utilitarista.

No entanto, não é tão simples distinguir as finalidades por detrás dessas concepções amplamente aceitas. Todos sabem qual a utilidade de um smartphone e de um tablet, mas nem todos sabem ou querem distinguir criticamente, no uso dessas tecnologias, seus aspectos éticosmorais. Ou seja, no modo de como elas facilitam a vida e, ao mesmo tempo, escravizam os homens às suas necessidades artificiais.

Castells considera que a informação é a matéria-prima que está na base do conhecimento e da comunicação entre as pessoas, afirma ainda que se vive em uma verdadeira sociedade de rede. Já sobre a sociedade do conhecimento enfoca que apesar da internet, "em princípio ser um canal de comunicação horizontal” em que as pessoas independentemente do status ou classe social a que pertençam podem aceder a todo e qualquer tipo de informação, a 177 verdade é que muitas das vezes, a realidade é muito distinta e por dois motivos: em primeiro lugar ficam de fora à partida todos os que não têm condições de acesso; em segundo lugar, porque o acesso à informação não é garantia que disso resulte conhecimento, e muito menos, aprendizagem (CASTELLS, 2003, p. 129).

Sobre a sociedade da aprendizagem, Fabela (2005) define a sociedade da aprendizagem ou "cultura aprendente" como um ambiente no qual a pluralidade de atores contribui para que haja a construção do conhecimento de forma partilhada, numa perspectiva contínua e processual, quer a nível individual ou coletivo, e em todos os domínios da sociedade. Dessa forma a sociedade da aprendizagem precisa construir o conhecimento de forma partilhada diante de uma pluralidade de atores sociais de natureza individual ou coletiva.

Diante de um mundo onde os fluxos de informações e as mudanças são permanentes transferindo para a educação um grande desafio para adequação às novas técnicas advindas do avanço dos meios tecnológicos digitais e a internet. O conhecimento é um recurso flexível, fluido, sempre em expansão e em mudança (HARGREAVES, 2003, p. 33).

\begin{tabular}{|l|l|l|l|l|}
\hline Qevista Dialectus & Ano 8 & n. 15 & Agosto - Dezembro 2019 & p. $171-180$ \\
\hline
\end{tabular}


Dessa maneira, os meios tecnológicos são adotados como ferramentas necessárias para a melhor obtenção de informação e conhecimento no processo de formação que condicionará as pessoas à adequação a esta nova realidade imposta na contemporaneidade.

Para o homem moderno ou contemporâneo, a tecnologia tem se tornado um meio e um fim a ser buscado. Nela está depositada a razão de existir no sentido de que na atualidade é forte a convicção de que o mundo só funciona por ela e para ela. Desse modo, a tecnologia se torna um equivalente funcional de uma nova metafísica e, como tal, uma categoria imediata para a interpretação e fundamentação do mundo moderno.

\section{Considerações finais}

Procurou-se defender ao longo deste artigo que a técnica em geral deve proporcionar aos homens, igualmente, meios para que estes possam viver bem. Que a técnica não pode servir de um pretexto para que se naturalize desigualdades que não são naturais, mas que são consequências do artificialismo causado pela cultura.

É precisamente o artificialismo do homem que Rousseau critica. Se uma sociedade passa a considerar toda a forma de artificialismo como natural, perde, de vista "o mais útil e necessário conhecimento de todos" que é exatamente "o conhecimento do homem", isto é, o autoconhecimento do homem enquanto ser natural. E não sabendo mais o que seja o homem, há o perigo que este seja reificado e transformado em mercadoria e em consumidor. Quando uma sociedade eleva os valores materiais acima da dignidade humana tem-se como consequência um desequilíbrio dos demais valores que estão na base da ordem social, quais sejam, a liberdade e igualdade.

Uma sociedade que é capaz de grandes realizações técnicas, que é capaz de transportar-se à lua, de mudar o curso das águas, de transformar enfim a natureza, mas que é incapaz de olhar dentro de si, não é uma sociedade que, segundo a concepção de Rousseau, tenha verdadeiramente progredido.

Uma outra ideia derivada da concepção de que a tecnologia preside o mundo moderno é o deslocamento do saber para os meios e o esvaziamento do sentido dos seus fins. Desse modo, defendemos que mais importante do que como se processam as coisas é para que (quem) elas se processam.

\begin{tabular}{|l|l|l|l|l|}
\hline Qevista Dialectus & Ano 8 & n. 15 & Agosto - Dezembro 2019 & p. $171-180$ \\
\hline
\end{tabular}


Portanto, é necessário considerar que não se pode negar a importância da tecnologia em si mesma, mas deve-se questionar os sentidos acerca de sua função social. Explicitar sua causalidade final a fim de compreender que, não obstante o fato de a tecnologia ser um recurso importante em todas as áreas da vida humana, inclusive na educação, seu uso não deve ser tornado absoluto na crença de que ela, por si só, resolverá os problemas humanos de aprendizagem e convivência, ainda mais considerando que a maior parte de toda a tecnologia desenvolvida continua a ser desenvolvida a partir das necessidades que ela mesma criou.

Igualmente não se pode deixar de pensar sobre as implicações morais advindas das concepções que privilegiam os meios e não os fins. Que tipo de homem a sociedade está formando? Ele viverá melhor que seus antepassados ou sucumbirá no abismo provocado pelas revoluções tecnológicas? Ou ainda que a humanidade não estaria caminhando para consumar os prognósticos de Nietzsche de que "a humanidade possui, no conhecimento, um belo meio para o declínio" ? (NIETZSCHE, 2007, p. 75)

Diante do exposto, pode-se questionar se de fato o homem do século XXI, não obstante o expressivo progresso técnico que tem acumulado ao longo da história tem contribuído para o melhoramento de si mesmo. Igualmente, é importante observar que a posição deste artigo não foi considerar a tecnologia nem "boa" nem "má". Para

Rousseau, a técnica pode ser o antídoto para os males que, em certa medida, ela própria tem causado. Assim, a técnica, entendida enquanto produto humano, deve estar a serviço da humanidade de modo a contribuir para a diminuição das injustiças e da desigualdade. Assim, o progresso da humanidade cuja expressão prática é a sua aplicação tecnológica não deve ser privilégio de poucas pessoas em prejuízo de muitas. Mas deve considerar sua função social na medida em que, sob uma perspectiva humana, a falta de acesso aos bens e serviços produzidos pela tecnologia devem ser distribuídos entre todos sob pena de se instituir, a partir da técnica, condições fundamentais para a desigualdade social.

\section{REFERÊNCIAS:}

CASTELLS, Manuel. A sociedade em rede. Tradução Roneide Venancio Majer. Atualização para a $6^{\text {a }}$ ed.: Juçara Simões. São Paulo: Paz e Terra, 1999.

\begin{tabular}{|l|l|l|l|l|}
\hline Qevista Dialectus & Ano 8 & n. 15 & Agosto - Dezembro 2019 & p. $171-180$ \\
\hline
\end{tabular}


HARGREAVES, Andy. O Ensino na Sociedade do Conhecimento: a educação na era da insegurança. Colecção Currículo, Políticas e Práticas. Porto: Porto Editora, 2003.

LÉVY, Pierre. Cybercultura. Traduação de Carlos Ireneu da Costa. São Paulo: Ed. 34, 1999.(Coleção Trans).

As tecnologias da inteligência: o futuro do pensamento na era da informática. Traduação de Carlos Ireneu da Costa. Rio de Janeiro: Ed. 34, 1993.

NIEETZSCHE, Freidrich Wilhelm (1844-1900). Sobre verdade e mentira. Organização e tradução: Fernando de Moraes Barros. São Paulo: Hedra, 2007.

ROUSSEAU, Jean Jacques. (1712-1778). Do contrato social; Ensaio sobre a origem das línguas; Discurso sobre a origem e os fundamentos da desigualdade entre os homens; Discurso sobre as ciências e as artes. Tradução Lourdes Santos Machado; introduções e notas Paul Arbousse-Bastide e Lourival Gomes Machado. 3a ed. São Paulo: Abril Cultural, 180 1983. (Os Pensadores).

SANTOS, Boaventura de Sousa. Um discurso sobre as ciências. $5^{\text {a }}$ ed. São Paulo: Cortez, 2008. 